\title{
A FABRICAÇÃO DE MÁRTIRES-ENCANTADOS E SUAS APROPRIAÇÕES POR COLETIVOS RURAIS E INDÍGENAS*
}

\section{Edimilson Rodrigues de Souza Celeste Ciccarone}

\section{Introdução}

A feira livre realizada semanalmente em Rondon do Pará (PA), no sudeste do estado, era uma das alternativas encontradas pela presidência do Sindicato de Trabalhadores Rurais (STR) do município para possibilitar a comercialização do excedente produzido pelos assentados e acampados da localidade. Era também um momento de encontro entre eles, oportunidade de rever os companheiros de luta e se informar sobre crédito agrícola, socializar conhecimentos sobre plantio etc. Contudo, em 13 de dezembro de

* Uma versão preliminar deste artigo foi apresentada no 36 Encontro Anual da Anpocs (2012), no grupo de trabalho "Estudos rurais e etnologia indígena: diálogos e intersecções". Agradecemos aos comentários de Emília Pietrafesa de Godoi, Maria Rosário Gonçalves de Carvalho e Maria Cristina Pompa.

Artigo recebido em 10/01/2013

Aprovado em 10/02/2014
2007, além da feira, foi organizado um manifesto para celebrar os sete anos do assassinato de Dezinho. ${ }^{1}$ Durante a manifestação, todas as vezes que o nome do sindicalista morto era pronunciado, os camponeses exclamavam: "Presente! Presente! Presente!".

Nas conversas dos camponeses - membros do STR, do Movimento dos Trabalhadores Sem-Terra (MST) e da Comissão Pastoral da Terra (CPT) da região de Marabá (PA) - apareciam com certa regularidade, naquela ocasião, temas como a luta pela terra, a reconstrução da memória da luta, das crenças e da ética do assentamento/acampamento; a ênfase, porém, estava na martirização dos líderes sindicais assassinados em áreas de intenso conflito.

\section{Etnografia e os grandes divisores}

A investigação da fabricação social dos mártires da terra ${ }^{2}$ tensiona questôes ainda abertas, pelo 
menos no campo das ciências sociais - trata-se de pensar noções que se tornaram totens antropológicos, para os quais constantemente são formulados argumentos de defesa frente às ciências que se nomeiam exatas (ou objetivas).

Para sustentar essa ideia, nos valemos da discussão de Eduardo Viveiros de Castro (2002) sobre a produção do conhecimento xamânico, elaborada numa das suas críticas às ciências exatas:

Conhecer bem alguma coisa é ser capaz de atribuir o máximo de intencionalidade ao que se está conhecendo. Quanto mais sou capaz de atribuir intencionalidade a um objeto, mais eu o conheço. O bom conhecimento é aquele capaz de interpretar todos os eventos do mundo como se fossem açôes, como se fossem resultado de algum tipo de intencionalidade. Para nós [cientistas], explicar é reduzir a intencionalidade do conhecido. Para eles [xamãs], explicar é aprofundar a intencionalidade do conhecido, isto é, determinar o objeto de conhecimento como um sujeito (Idem, pp. 487-488).

Considerando o argumento exposto, a intenção deste artigo se concentra nas possibilidades de descrição e tradução do movimento de trânsito (incorporação) das almas dos "mártires da terra", que parece provocar uma trajetória do corpo individual ao coletivo, ${ }^{3}$ indicando uma possível fabricação da imagem do mártir, que (re)elabora a alma como agente mediador na luta. ${ }^{4}$ Isso ocorre na medida em que as narrativas sobre esses líderes assumem potencialidades agenciativas, seja na inscrição destes corpos nos movimentos de resistência, seja nas práticas e estratégias no interior dos seus respectivos coletivos.

Todo ser a que se atribui um ponto de vista será então sujeito, espírito; ou melhor, ali onde estiver o ponto de vista, também estará a posição de sujeito. Enquanto nossa cosmologia construcionista pode ser resumida na fórmula saussureana: o ponto de vista cria o objeto - o sujeito sendo a condição originária fixa de onde emana o ponto de vista -, o perspectivismo ameríndio procede segundo o princípio de que o ponto de vista cria o sujeito; será sujeito quem se encontrar ativado ou "agenciado" pelo ponto de vista (Castro, 2002, p. 373).

No entanto, essa investida etnográfica é prescrita num campo minado da teoria antropológica, e é preciso utilizar conjuntamente ferramentas de análise historicamente separadas pelo campo disciplinar para dar conta do entendimento acerca das narrativas sobre esses líderes. Esse exercício de superação da grande divisão - natureza versus sociedade (cultura) - foi sugerido por Bruno Latour (2009) e inspirou análises de outros autores em contextos diversos. Abordaremos aqui algumas delas, sem a pretensão de articulá-las, mas retomar sua contribuição específica e, a partir de cada uma, avançar na leitura e na análise das narrativas rituais sobre os mártires da terra.

Nossas atenções estão localizadas fundamentalmente nas proposiçóes de Latour (2009, pp. 91-93) acerca do que ele nomeia de antropologia simétrica, capaz de reestabelecer continuidades em vez de separações. Nessa perspectiva, os processos de simetrização que aparecem na economia do pensamento latouriano livram-nos das grandes divisões epistemológicas, na medida em que reconhecemos produções de naturezas-culturas:

Isto porque o objetivo do princípio de simetria não é apenas o de estabelecer a igualdade - esta é apenas o meio de regular a balança no ponto zero - mas também o de gravar as diferenças, ou seja, no fim das contas, as assimetrias, e o de compreender os meios práticos que permitem aos coletivos dominarem outros coletivos. [...] Esses quase-objetos, com suas trajetórias hesitantes, traçam ao mesmo tempo formas de natureza e formas de sociedades [...] (Idem, pp. 105-106).

Nesse ponto, Latour adverte que as diferenças não podem ser negadas (erro do relativismo) nem maximizadas (erro do universalismo), mas reconhecidas como diferenças de tamanho e de corte, como as volutas sucessivas de uma espiral. Esse exercício nos dá condições de considerar a coexistência das diferenças e das semelhanças. 
Goldman e Lima (1999) levantam questóes sobre alguns elementos que se encontram disseminados pela antropologia contemporânea, reformulados e reforçados a partir da tendência do pensamento antropológico em opor "nós" e "eles". Essas operações de cunho epistemológico, que tensionam problemas etnográficos, são mecanismos que produzem assimetrias baseadas em seis operações principais: identificação; sinédoque; desproporção; projeção; juízo de relação como atributo do objeto; e sobrecodificação. Nos ateremos a dois desses procedimentos. Com relação à operação de identificação, os autores argumentam que a Grande Divisão exige uma identificação a priori que funcione como base de comparação para se ter uma suposta garantia de comensurabilidade. Esses esforços, na perspectiva dos autores, orientam a produção de assimetrias de uma concepção substancialista daquilo que se separa - e sugerem:

[...] que não existe uma diferença genérica e invariável (simples contraface da identidade), mas modalidades de diferença que diferem entre si. Não basta afirmar que somos diferentes dos outros como eles são diferentes entre si; seria preciso estabelecer, caso a caso, a modalidade de diferença com a qual nos defrontamos. Em suma, pensamos que a questão "o que, em geral, nos aproxima e/ou distingue dos outros" é inadequada e não deveria ser formulada (Idem, p. 85).

A segunda operação que sustenta a análise proposta neste artigo, especificamente, relaciona-se à transformação de juízo de relação em atributo do objeto, ponto em que colapsos entre metodologia e ontologia são comumente identificados, quando nos esquecemos do caráter relacional e metodológico desse juízo e tomamos o diferencial como atributo do objeto, condenando os indivíduos a uma infinita repetição das práticas socioculturais.

Como modelos desse gênero nunca se adaptam bem aos materiais etnográficos, é preciso imaginar algo como um "retorno do recalcado": ora o indivíduo irrompe, ameaçadora ou marginalmente, no seio da sociedade; ora a totalidade reaparece, corrompida ou derrisória, entre os indivíduos. Como se "sociedade", "indivíduo”... fossem coisas em si cuja eliminação só pode ser ideológica e parcial, e não noções e artifícios metodologicamente construídos para conferir alguma inteligibilidade ao que investigamos (Idem, p. 89).

Nos estudos ora apresentados, a proposta nos parece eminentemente teórica e epistemológica, naquilo que se tem convencionalmente chamado de história da ciência ou de filosofia da ciência.

Ana Maria de Niemeyer e Emília Pietrafesa de Godoi (1998) indicam a possibilidade de que estudos antropológicos realizados em distintos campos empíricos podem se fecundar reciprocamente. A discussão, retomada por Godoi e Nashieli Rangel Loera (2009-2010), volta a apontar para a insatisfação com as "grandes divisóes" estabelecidas pela pesquisa antropológica no que tange a separação entre etnologia indígena e etnografia rural, articulando questões de caráter fundamentalmente etnográfico.

No caso brasileiro, assistimos, hoje em dia, a caboclos que se "redescobrem" índios, seringueiros que se "transfiguram" em povos da floresta, ribeirinhos que se "descobrem" população tradicional, trabalhadores rurais que "se tornaram" quilombolas, agricultores tradicionais transmutados em comunidades de fundo de pasto, e mais recentemente populações indígenas que se "tornam" sem-terra, pois numa tentativa de retomada de terras consideradas por eles como ancestrais ocupam uma propriedade ou beiras de estrada e montam acampamentos, estratégias que até pouco tempo atrás estavam relacionadas a trabalhadores rurais (Idem, p. 9).

As questôes que atravessam todas essas relaçôes recombinam demandas da luta por reconhecimento, materializadas em defesas de projetos de vida coletivos, e nos dão condições para questionar abordagens analíticas tradicionais, que também podem ser recombinadas para dar conta de sujeitos e movimentos que "transitem" entre universos rurais e indígenas. Arriscamo-nos a sugerir que os acontecimentos que marcaram a região do Bico do Papagaio, na foz do rio Araguaia, os quais compóem o 
lócus deste trabalho, contêm indícios da fragilidade dessa separação instituída pela antropologia entre povos indígenas, de um lado, e camponeses e quilombolas, de outro, como categorias sociais excludentes ou no máximo relacionadas pelos chamados contatos interétnicos (Oliveira, 1976).

Se esses sujeitos articulam-se na luta, o processo de sacralização parece funcionar como um dispositivo que, através da convergência e da incorporação, mais do que relacionar, parece ultrapassar na figura do mártir, nas diferentes categorias sociais.

Os estudos sobre as tensões e confrontos que marcam a ocupação humana na Amazônia e as romarias e narrativas sobre líderes sindicais assassinados em decorrência desses conflitos demonstram essas e outras conexôes possíveis nas lutas cotidianas por direitos e reconhecimento. Tentaremos contextualizar essas dinâmicas sociais por meio da identificação e da análise de narrativas (rituais) em torno de líderes sindicais e agentes pastorais assassinados em conflitos agrários, qualificados como "mártires da terra" e/ou "encantados".

Buscamos compreender também os efeitos das imagens (emblemas) e dos sons na constituição dessas "sociedades inacabadas", construídas "às margens das margens" do campesinato brasileiro, olhando e ouvindo - ou pelo menos tentando os gritos, os ruídos e os silêncios nesses espaços de conflito, tensão, mediação e intermediação performáticas (Turner, 1986; 2005; 2008; Ciccarone, 2003; Dawsey, 2005; 2006). O que se tem notado é que, enquanto o Estado é omisso e conivente com o agronegócio e o latifúndio nessas áreas, coletivos rurais se articulam com auxílio de agentes mediadores e protagonizam histórias de luta pelo direito de permanecer no lugar e resistir à sua expulsão de suas propriedades. Para tanto, reconstroem relaçôes, repensam posições, formas de ação, refazem alianças e ritualizam os líderes mortos como estratégia de fortalecimento da resistência do grupo.

Enquanto esperam longamente pelas açôes dos órgãos governamentais, ressignificam a luta pela terra e pela vida (Comerford, 1999) e constroem novos sentidos para a morte, num continuum articulado corpo-alma-grupo, numa simetria entre materialidade e imaterialidade. Seus "dominadores" são enfrentados com a mesma força ou com forças maiores, e seus líderes "mortos" parecem - ao que tudo indica - assumir novos papéis.

Rodolfo Lunkenbein, Xicão Xukuru e Simão Bororo (mártires da terra indígena), Josimo Morais (mártir dos pobres lavradores do Bico do Papagaio), Chico Mendes (mártir da floresta), Francisco Jentel (mártir do povo do Araguaia), Margarida Alves (mártir das mulheres lavradoras), Marçal Tupã'I e Sepé Tiaraju (mártires da causa indígena), Antônio Conselheiro (mártir do povo sertanejo), Dorothy Stang (Mártir da Criação), João Bosco (mártir da luta contra a tortura e da reforma agrária) e Gringo (mártir do sindicalismo) são alguns exemplos de como a morte é ressignificada por esses coletivos.

Seus nomes e suas imagens são sempre lembrados em reuniōes, atos públicos e romarias, na Amazônia e em outras partes do país, entoados como hinos de guerra e reforçando a resistência, a cooperação e a continuidade, o que contraria a intenção de latifundiários que acreditam na morte do líder como finalização da resistência.

Dessa forma, eles se transformam em símbolos de luta e resistência, uma referência de dedicação, missão e doação - no sentido de dar-se até as últimas consequências - pelas causas dos trabalhadores do campo e pelas "causas maiores da humanidade" (Murphy, 2008).

\section{Repertórios de resistência}

Todos esses desdobramentos, marcados por diversos tempos históricos, ${ }^{6}$ inscrevem sujeitos de distintas origens numa cosmografia ${ }^{7}$ na qual encontram motivos para resistir ao modelo sincrônico de ocupação de terra pois justificam a permanência com base em referenciais diacrônicos (tradicionalidade da ocupação, fluxos migratórios em grupos familiares ou de afinidade, tempo de chegada, sucessão de domínio e trabalho investido). Esses argumentos são acessados regulamente, adiante das ameaças de desocupação e desapropriação por parte dos órgãos governamentais ou da grilagem.

A Amazônia oriental tem se constituído em lugar de projeção de sonhos e esperanças para migrantes vindos de todos os lados, especialmente 
nordestinos. No inicio do século a exploração da borracha, que se fez em grande parte com a mão de obra nordestina, se apresentou como uma alternativa para aqueles que viam esgotadas as possibilidades de sobrevivência na região de origem. O garimpo de cristal em Goiás atraiu muita gente na década de 30 e 40 . O povoamento de Tocantins, sul do Maranhão, sul do Pará se fez principalmente por piauienses, cearenses, baianos. Para os sertanejos nordestinos a Amazônia era sinônimo de mata, de verde, contraposta à sequidão do sertão, possibilidade de plantio, de fartura. Nesta perspectiva, famílias inteiras migravam contando com a possibilidade de se apropriarem de áreas que, em princípio, não interessavam aos grandes donos de terra. Mataria bruta, sem sinal de cristão, onde se tinha que enfrentar feras e índios, onde era necessário amansar o lugar (Vieira, 2001, p. 111).

O acesso a um repertório narrativo e ritualístico de elementos mítico-históricos (Sahlins, 1985), diacrônicos e/ou sobrenaturais revela o cunho pronominal da luta pela terra, na medida em que se alternam e inscrevem pontos de vista paralelos ou contrários ao discurso oficial sobre o direito à propriedade privada. Nessa direção, a ritualização de líderes sindicais mortos em espaço de intensos conflitos pela posse da terra e de disputas de território e poder parece funcionar como modelo para a ação de sujeitos submetidos pelo poder das oligarquias locais à lógica da monocultura e da criação de gado em larga escala.

São organizadas formas de articular práticas rituais e posturas políticas com a finalidade de fortalecer os grupos minoritários que se veem desolados frente ao poder dos antigos coronéis travestidos de novos agropecuaristas. A Romaria dos Mártires da Caminhada é um bom exemplo disso: trata-se de uma peregrinação que reúne grupos camponeses, comunidades negras rurais (quilombolas), povos indígenas, líderes sindicais, agentes pastorais e ativistas políticos de diversas regiôes do Brasil e do mundo em Ribeirão Cascalheira, na região nordeste do Mato Grosso. ${ }^{8} \mathrm{O}$ município é centro da topografia sagrada, referência na celebração dos mártires e sede da Galeria dos Mártires da América Latina. No local, foi assassinado em 1976 o padre João Bosco Penido Burnier, mineiro de Juiz de Fora, jesuíta e missionário que atuava entre os índios bacairis. A morte dele e os acontecimentos que a sucederam foram relatados por dom Pedro Casaldáliga9 durante a Romaria dos Mártires da Caminhada em julho de 2011.

Era tarde do dia 11 de outubro de 1976. Duas mulheres sertanejas, Margarida e Santana, estavam sendo torturadas na cadeia-delegacia de Ribeirão Bonito, lugar e hora de latifúndio prepotente, de peonagem semiescrava e de brutalidade policial. A comunidade celebrava a novena da padroeira, Nossa Senhora Aparecida. Nesse dia eu havia chegado ao povoado com o padre João Bosco. Nós dois fomos interceder pelas mulheres torturadas. Os policiais nos esperavam no terreiro da delegacia e apenas foi possível um diálogo de minutos. Um soldado desfechou no rosto do padre João Bosco um soco, uma coronhada e o tiro fatal. Em sua agonia, padre João Bosco ofereceu a vida pelo Cimi [Conselho Indigenista Missionário] e pelo Brasil, invocou ardentemente o nome de Jesus e recebeu a unção. Foi morrer, gloriosamente mártir, no dia seguinte, festa da Mãe Aparecida, em Goiânia, coroando assim uma vida santa (dom Pedro Casaldáliga, entrevista concedida em 15/7/11).

O missionário morto havia sido confundido com o bispo Casaldáliga, ameaçado por fazendeiros da região por seu envolvimento na defesa das lutas fundiárias de posseiros e índios. A Galeria dos Mártires, conhecida também como Santuário dos Mártires da Caminhada, foi construída no mesmo lugar em que o padre João Bosco foi baleado, como um protesto dos moradores de Ribeirão Cascalheira, que anteriormente, no sétimo dia da morte do referido padre, destruíram a delegacia.

$\mathrm{Na}$ Galeria são abrigadas imagens de líderes assassinados em decorrência de conflitos fundiários, reconhecidos por sua atuação diante dos movimentos sociais e classificados como mártires da tortura, da terra indígena, da floresta, da verdade, da discriminação, da causa negra, do povo sertanejo, entre outras denominações. 

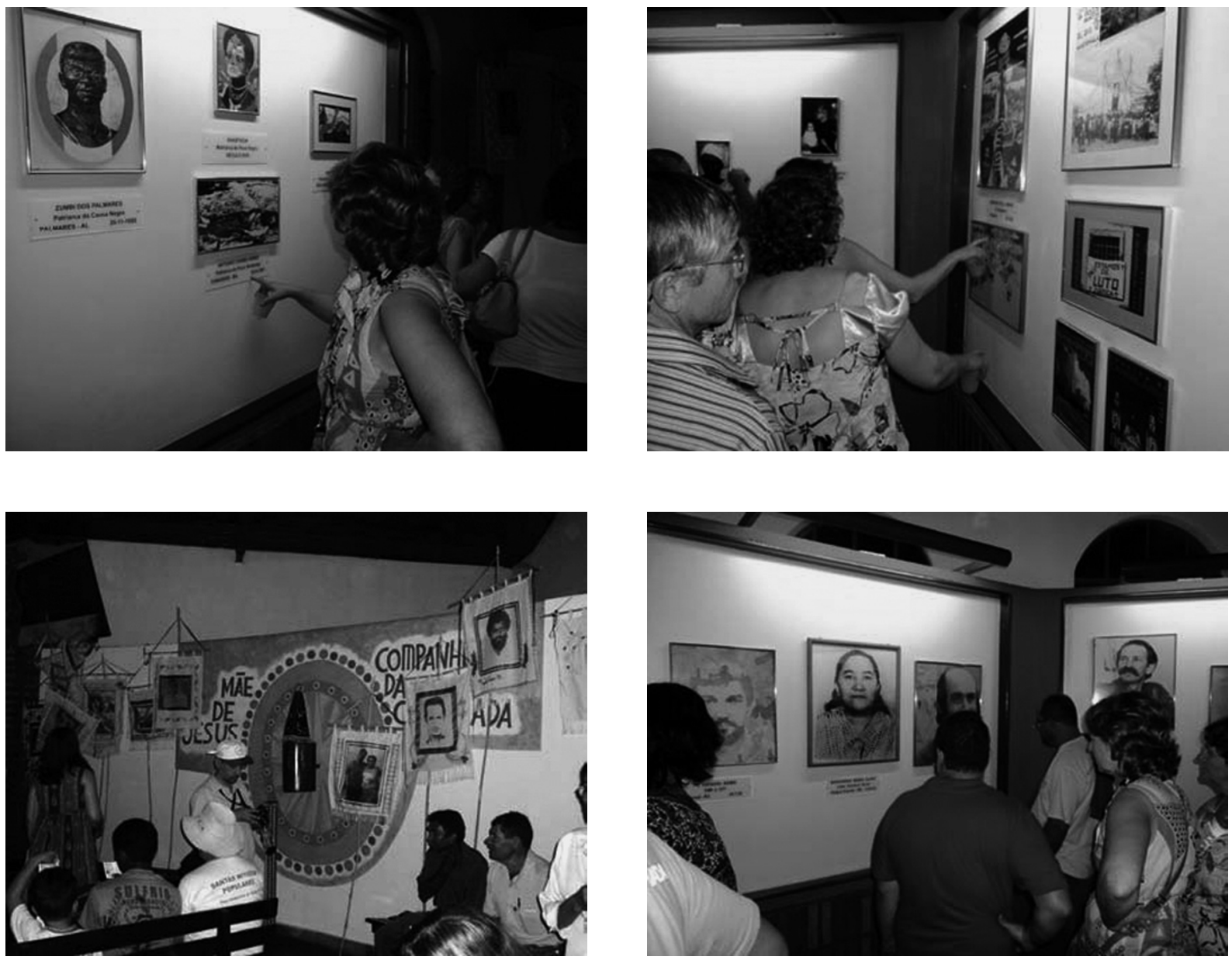

Concentração de romeiros na Galeria dos Mártires da América Latina, em Ribeirão Cascalheira (MT). Foto: Edimilson Rodrigues, 2011.

A Romaria atualiza o percurso feito por João Bosco e Casaldáliga, bem como o caminho dos posseiros que retornaram à delegacia para destruí-la e depois construir a Galeria dos Mártires.

Esses elementos tornam possível reconhecer e potencializar a cosmografia de Ribeirão Cascalheira, que assume outras formas a partir das narrações dos enfrentamentos e resistências desses mártires, as quais, ao reapresentá-los, recriam o tempo-espaço vivido. $\mathrm{O}$ acesso a essas lembranças - que contemplam os locais e as pessoas envolvidas nos conflitos e são atravessadas por suas histórias de vida e experiências cotidianas - cria "lugares-de-memória ${ }^{10}$ das práticas de resistência e de luta em defesa de projetos de vida e reforma agrária.
A Romaria, que comemorou quarenta anos em 2011, reuniu, de acordo com seus organizadores, aproximadamente 1600 romeiros, vindos de todas as regiōes do Brasil e de outros países, como Alemanha, Espanha e Itália. Entre eles, estavam presentes representantes do Conselho Indigenista Missionário (Cimi), da CPT e dos povos indígenas guarani, caiouá, xucuru e xavante. Cada romaria é preparada ao longo de cinco anos, logo que se encerra a anterior, sendo de responsabilidade das comunidades da prelazia de São Félix do Araguaia a confecção de painéis, a provisão de alimentos e a organização da hospedagem dos romeiros, sempre de forma coletiva.

Nos três dias que antecedem o ritual são realizadas celebrações que desencadeiam o processo 

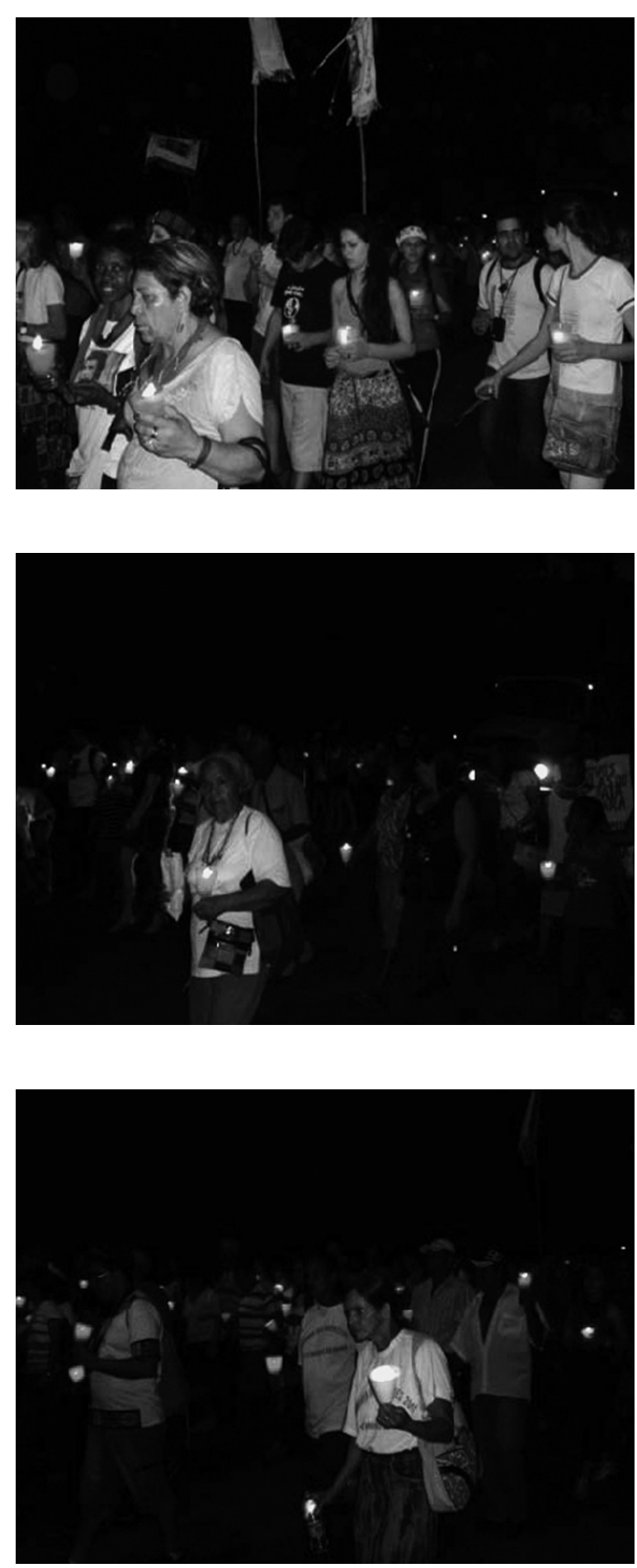

Peregrinos e romeiros na Romaria dos Mártires da Caminhada, Ribeirão Cascalheira (MT). Foto: Edimilson Rodrigues, 2011. de elaboração da sacralização dos mártires através da partilha de suas histórias. Numa dessas noites registramos a acolhida dos romeiros na capela que teria sido onde o padre João Bosco recebeu os primeiros socorros antes de ser levado para a cidade de Goiânia e falecer. Os momentos que precedem o ritual são marcados por cantos, danças e exposição de imagens que contribuem na montagem expressiva das narrativas sobre as histórias dos líderes magnificados.

$\mathrm{Na}$ alegria desta noite, marcada pela lua que vem nos beijar neste momento em que estamos pisando em um chão sagrado, no lugar desta capela, lugar da esperança, muitas crianças nasceram aqui, muitas vidas foram salvas nesta casa, era onde morava a equipe pastoral, mas é também a casa do momento martirial do padre João Bosco. Estamos aqui, pisando neste chão, e na beleza de quem veio de tantos lugares, e aí a gente quer acolher cada um e cada uma para esta noite, para este encontro, para este momento de louvor e de ação de graças. E a gente acolhe com muita alegria os que vieram do Paraná, de Minas Gerais, de Vitória, de São Paulo, do Mato Grosso, da Itália, da Alemanha, da Espanha, da Bahia, de Santa Catarina, da Amazônia, de Ribeirão Cascalheira, do Rio de Janeiro, de Goiás, de Brasília. [...] Estamos em romaria, caminheiros e caminheiras, e a gente traz o cansaço da viagem. E aqui a gente vem buscar a água viva, a vida e o testemunho dos mártires. Celebrar nesta noite esse cansaço, mas a alegria da chegada, a alegria de estarmos aqui, de celebrar nossas vidas (padre Mirim, em entrevista concedida em 15/7/2011).

Os relatos dos agentes pastorais atualizam a postura política e ideológica dos mártires, e nesse momento também são suscitados episódios de resistência, atos de enfrentamento e confrontos com órgãos do Estado e latifundiários. A ritualização e sacralização da luta cotidiana, ao romper com as estruturas estabelecidas, possibilita a insurgência de outras formas político-religiosas de participação.

Referindo-se às romarias dos mártires do Caaró e da Terra, ${ }^{11}$ Carlos Alberto Steil (2004) mostra 
que há, nessas peregrinações, um esforço de fazer uma "leitura projetiva do passado mítico e histórico como traduções e transvalorizações possíveis da experiência presente", de modo que a evocação da figura do herói mítico permite construir "uma continuidade entre sujeito e signos do passado e atores e agentes sociais marginalizados do presente: índios, negros, colonos sem-terra" (Idem, p. 12), constituindo-se num lugar privilegiado de elaboração social de uma narrativa e de um personagem.

Victor Turner (1986; 1987; 2005; 2008), por sua vez, reconhece a importância da liminaridade como condição para contestação da estrutura no interior da sociedade ao organizar sequências de eventos categorizados como dramas sociais. Para o autor, a eclosão do conflito faz com que aspectos fundamentais da sociedade, reconhecidamente encobertos por costumes e hábitos cotidianos, revelem-se (ou apresentem-se) de maneira mais acentuada (Turner, 2008, p. 31). Os dramas sociais, como modelos e metáforas elaboradas pelos atores, correspondem a fases de ação simbólica - ruptura, crise, ação corretiva e reintegração - que se articulam sob a forma de processos comunicativos, nos quais são reconhecidos "símbolos, signos, sinais e marcas, verbais e não verbais, que as pessoas empregam para alcançar metas pessoais e do grupo" (Idem, pp. 32-33).

A partir do modelo processual do drama social, Turner faz uma análise sobre os símbolos rituais associados a um grupo de peregrinações religiosas, de diferentes origens, objetivando pensá-las como unidades processuais e antiestruturas, com foco na semântica dos símbolos rituais (Idem, pp. 154-155).

Para o autor, esses eventos apresentam um caráter de communitas, ${ }^{12}$ uma vez que são organizados em espaços liminares. A communitas pode ser classificada em três tipos, distintos em função da natureza e do laço social dos atores: existencial ou espontânea; normativa; e ideológica. ${ }^{13}$ Turner adverte que, enquanto a situação geral estimula o surgimento da communitas do tipo existencial, é a normativa que caracteriza os laços sociais que emergem tanto entre os peregrinos quanto entre estes e os que lhes oferecem algum tipo de ajuda ou hospitalidade (Idem).

Nesse bojo analítico é perceptível que há um diálogo persistente entre a vida cotidiana e as viagens de peregrinação, que possibilita uma transfor- mação constante entre a communitas existencial e a normativa:

[...] quando aqueles que fazem estas manifestações querem que elas perdurem na comunidade e buscam seus símbolos para salvaguardar sua persistência, tais símbolos tendem a ser extraídos do repertório de grupos de communitas ao longo dos tempos e transmitidos à era atual através da escrita e de outros códigos simbólicos. Assim, existe uma interinfluência entre as formas novas e tradicionais de communitas, o que em alguns casos, leva à recuperação de formas tradicionais há muito enfraquecidas ou esmaecidas (Idem, p. 160)

As romarias, como communitas, tencionam o deslocamento da instituição para a sociedade, "um deslocamento da Igreja para o Reino de Deus", numa tentativa de articular - nas lutas camponesas, indígenas, quilombolas, entre tantas outras - a busca pela terra prometida, a "terra sem males". Nessa direção se encaminha o discurso emblemático de dom Pedro Casaldáliga de relativização da instituição, por meio da conversão dos missionários aos índios, com vistas à "construção de uma sociedade liberta” (Steil, 2004, p. 21). ${ }^{14}$

\section{Imagens, totens e palavras de ordem}

Os temas apresentados neste texto ganharam maior nitidez a partir dos fatos narrados no documentário Esse homem vai morrer: um faroeste caboclo (Gallo, 2008). No filme - gravado em Rio Maria, Xinguara, Marabá e Rondon do Pará, localidades no sul do Pará marcadas pela violência, terror e assassinatos - são apresentadas listas de agentes pastorais e líderes sindicais marcados para morrer, em especial ativistas de movimentos sociais, como em cooperativas de assentamentos, nos Sindicatos de Trabalhadores Rurais (STRs), nos Movimentos de Atingidos por Barragem (MABs), nos Movimentos de Educação de Base (MEBs), na Comissão Pastoral da Terra (CPT), entre outros.

Mencionando Santiago Nasar, personagem de Gabriel García Márquez, em Crônica de uma morte 
anunciada (2012), Ricardo Rezende recorda que, no caso desse personagem, "a cidade toda sabia que ele iria morrer, mas ele não sabia”. No entanto, os assassinatos no sul do Pará, assumem uma configuração particularmente complexa, pois "todos sabem!", exclama Ricardo, "até a vítima sabe!" que vai morrer. Nessas localidades uma sequência de mortes é registrada numa lista e anunciada, e o canto se repete: "ele (ela) vai morrer!” (Idem). Esses elementos destacados, e tantos outros presentes na referida região, remontam às consequências de uma ocupação que, desde sua gênese, subsidiava os grandes agropecuaristas e desconsiderava a presença dos pequenos núcleos de famílias camponesas e povos indígenas que lutavam para permanecer em seus lugares (suas terras), a fim de garantir sua sobrevivência (Velho, 1976; 1982; DaMatta e Laraia, 1978; Ianni, 1978; Martins, 1980 e 1984; 2009; Figueira, 1986; Esterci, 1987; Guerra, 2001; Hébette, 2004).

Descrita por José de Souza Martins (2009), a efervescência dos conflitos entre indígenas, camponeses e fazendeiros na fronteira amazônica demarcara espaços e posições dos atores em cena.

Não só os índios da fronteira foram envolvidos na luta violenta pela terra. Também os camponeses da região, moradores antigos ou recentemente migrados, foram alcançados pela violência dos grandes proprietários de terra, pelos assassinatos, pelas expulsões, pela destruição de casas e povoados. Entre 1965 e 1985, quase seiscentos camponeses foram assassinados em conflitos na região amazônica, por ordem de proprietários que disputavam com eles o direito à terra (Idem, p. 133).

Os relatos das experiências de violência vividas por grupos de indígenas e camponeses locais, que originam por meio da morte a condição de martírio, permitem, entre outras coisas, o entendimento acerca da constituição desses atores que emergem numa região de fronteira.

Os dados etnográficos recolhidos nas idas a campo ${ }^{15}$ reforçam a eminência de uma prática que tem se repetido nessas regiōes: o assassinato por encomenda, executado por jagunços e pistoleiros locais.
Ameaças circulam pelas ruas dos povoados a anunciar as mortes e a preparar seu advento. Torna-se comum ouvir que "todos já sabem (ou já sabiam): esse homem vai morrer!”. No entanto, o que deveria assustar e acovardar esses líderes, conforme as intenções dos mandantes (os latifundiários), tem apresentado efeitos contrários, posto que as ações são revigoradas e as intimidações parecem estimular e encorajar uma participação cada vez mais ativa à frente dos movimentos de luta e resistência.
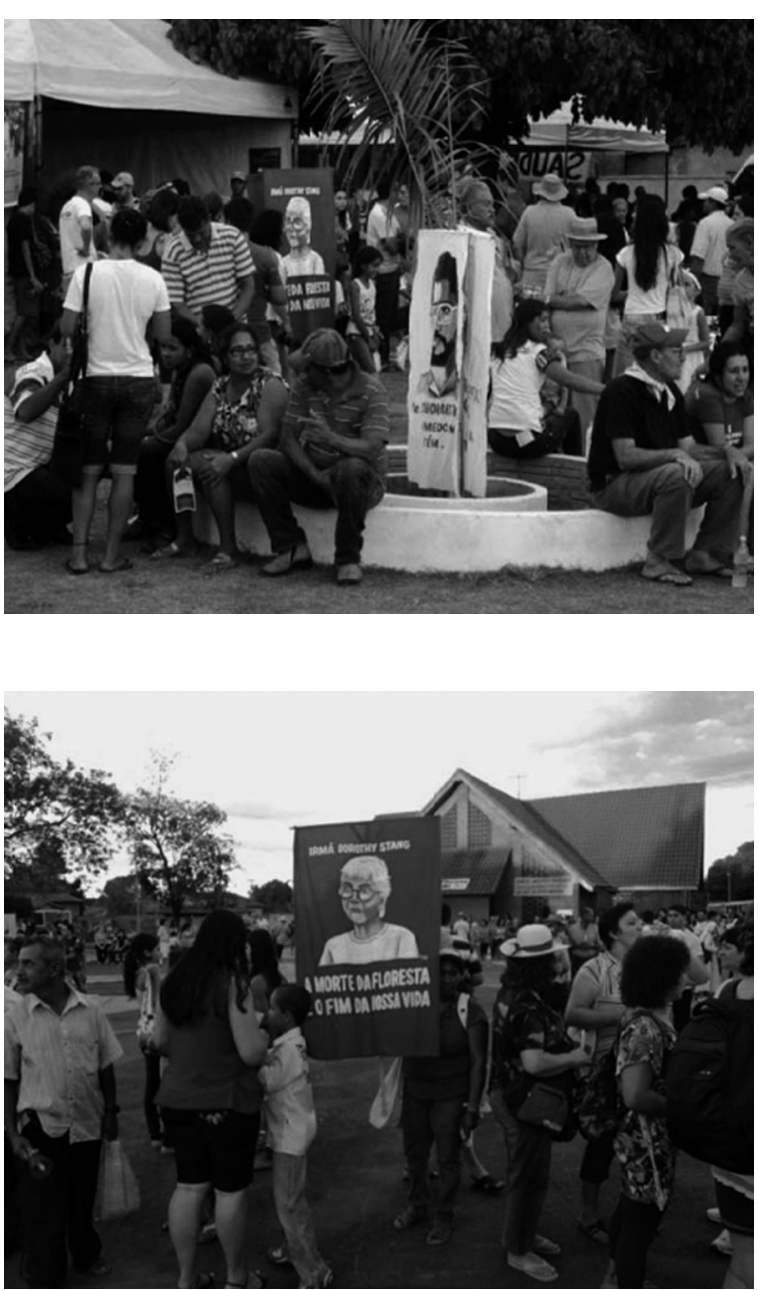

Peregrinos e romeiros na praça central de Ribeirão Cascalheira. Em destaque, as imagens de padre Josimo (assassinado em 1986) e Dorothy Stang (assassinada em 2005). Foto: Edimilson Rodrigues, 2011. 
Isso nos leva a interrogar se esses agentes não estariam imersos em lógicas de encantamento, posto que os sacrifícios (Mauss e Hubert, 2005) aos quais eles se submetem ou são submetidos levaram os seus pares a classificá-los ou qualificá-los como mártires encantados. A força do encantamento na fabricação do mártir ganha evidência na imagem do cacique Xicão Xukuru, assassinado a tiros na cidade de Pesqueira (PE), em 20 de maio de 1998, a mando de fazendeiros locais. A narrativa de sua viúva, Zenilda, na Romaria dos Mártires da Caminhada ilustra a trajetória do cacique, tornado encantado nas memórias do povo xucuru.

Quero dizer a vocês que não só do povo xucu$\mathrm{ru}$, mas em todos os parentes indígenas já teve bastante sangue derramado e não só indígena como daqueles que apoiam nossa causa. Mas queria dizer a todos vocês que esse sangue volta pras nossas veias e nos encoraja, porque quem nasceu pra morrer lutando, não vai morrer de braços cruzados.

E aqui eu vou cantar um cântico dos irmãos de luz, dos encantados, porque aqueles nossos que se vão, pra nós, eles não morreram, eles continuam vivos no nosso meio. [...] Salve os encantos de luz!

Esses encantados estão conosco índios, e com todos vocês que lutam por nós (Zenilda, 17/7/2011).

Há um sinal da produção de efeitos simbólicos causados pelas imagens desses homens "marcados para morrer" e da confiança dos seus pares numa vida que se renova constantemente, numa força que não se esgota com a morte deles, ocorrendo o oposto do esperado pelos mandantes. Nessa direção, encontram-se indícios de que o grupo reelabora a figura do líder (fabrica-o) e os enfrentamentos potencializam-se após sua morte.

\section{A potencialidade agenciativa das imagens}

No painel Cristo libertador, ${ }^{16}$ de Mario Aldighieri, encontrado na Igreja Cristo Libertador de
São Geraldo do Araguaia (PA), é possível reconhecer alguns dos mecanismos responsáveis pela fabricação dos mártires-encantados, indicando as potencialidades evocativas dessas imagens nos atos de circulação de conhecimentos e de produção da memória do grupo. Nesse painel, as imagens deixam de ser ícones da luta para tornarem-se agenciadoras dos atos de resistência e enfrentamento. Transformam-se em fontes de memória, mas não de uma memória presa ao passado; ao que tudo indica, essa memória imagética tensiona um devir atravessado pela evocação das experiências de apropriação da terra, das lutas a muito revivida pelo reconhecimento de suas ocupações e das constantes peregrinações em busca de terra para plantar e viver.

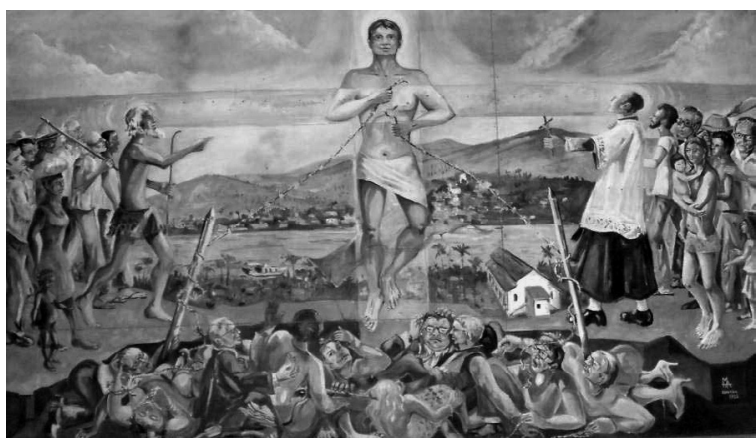

Painel do "Cristo Libertador", de Mario Aldighieri, São Geraldo do Araguaia (PA).

Foto: Edimilson Rodrigues, 2010.

Verifica-se uma intencional aproximação entre as imagens sacralizadas (Cristo, São João Batista e São Geraldo Majella) e agentes mediadores, alguns já assassinados, outros, "marcados para morrer” (padres Aristides Camio e Francisco Gouriou, dom José Patrick Hanrahan, dom Pedro Casaldáliga, padres Ricardo Rezende e José Maria Cavalcante Costa, Raimundo Ferreira Lima e sua esposa Oneide). Há também uma referência direta aos algozes da luta pela terra na região, particularmente no período da Guerrilha do Araguaia (1972-1974), ${ }^{17}$ os quais seriam "vencidos pela força da fé e da união”. 
E se Marcel Mauss (2003, p. 356) estiver certo ao citar Whitnell, quando este expressa que alguém que "se crê enfeitiçado salva-se ao entoar o canto sagrado de seu clã, de seu antepassado", tornando-se invencível? Parece ocorrer um movimento parecido entre esses grupos de camponeses (posseiros, meeiros, acampados, assentados), agentes pastorais e líderes sindicais, materializado na crença da figura do líder morto como sinal de resistência e continuidade na (e pela) luta.

Reconhecemos nesses movimentos questões importantes sobre usos dessas imagens não como ilustrações, mas como textos, potências narrativas capazes de (re)criar o mundo, na medida em que agenciam novos atores em suas "lutas" (Carminati, 2011). Se for assim, podemos sugerir que essas imagens são instituintes, sempre inacabadas, de movimentos de luta e resistência; melhor dizendo, objetos de constantes atos de recriação e reapresentação dos enfrentamentos em defesa dos projetos de vida desses grupos.

Portanto, investir no trabalho de entendimento da produção e manejo dessas imagens, como nas narrativas sobre elas, objetiva compreender essas modalidades de tradução dos significados atribuídos aos assassinatos de líderes sindicais em regiōes de intensos conflitos fundiários; compreender, sobretudo, o sentido que essas "mortes" têm na fundamentação de narrativas de luta e resistência dos agentes de mediação e dos coletivos rurais e indígenas.

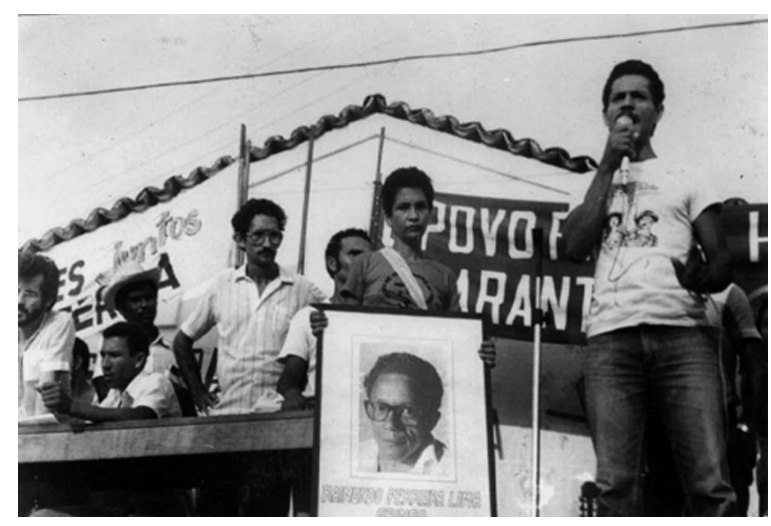

Maria Oneide num ato público em São Geraldo do Araguaia (PA), destacando a imagem de Gringo, líder sindical assassinado. Foto: arquivo particular.
Assim, um investimento na análise dessas imagens intenciona dar voz e visibilidade aos sujeitos violentamente silenciados, já que as narrativas visuais são uma forma privilegiada de evocar e transmitir a memória desses grupos.

Essa relação entre a imagens-memória e os enfrentamentos cotidianos evoca o estudo de Emília Pietrafesa de Godoi (1998) no sertão do Piauí, cuja perspectiva é de que as narrativas intencionam a transmissão dos acontecimentos que marcaram a vida dos grupos, desdobrando-se em regiōes da memória na medida em que

[...] envolve o indivíduo e se confunde com o tempo, fazendo com que esses sertanejos não só vivam em um tempo, mas em uma memória. A memória não está dentro deles, antes são eles que se movem dentro de uma "memória-mundo" [...]. Nesta memória-mundo, não se trata, para o indivíduo, de se apreender a si mesmo dentro de um passado pessoal, mas de se situar em uma ordem geral, de estabelecer, em todos os planos, a continuidade entre si e o mundo, ligando sistematicamente a vida presente ao conjunto do tempo (Idem, p. 101).

A relação entre memória e espaço atravessa o cotidiano desses grupos também na fronteira amazônica: essas imagens-memórias transitam por diferentes tempos e passam a atualizar continuamente os significados e sentidos para a luta, além de fortalecê-los, pois há sempre novos mártires e a matriz dos significados se perpetua com novos sentidos, fazendo emergir novos personagens a partir da relação entre sujeito-imagem, traduzida numa relação sujeito-sujeito. As narrativas em torno dos mártires-encantados, sob a perspectiva dos painéis que os convertem em baluartes da defesa de projetos de vida e do direito de permanecer nas terras ocupadas -, revivem suas experiências de vida e seu engajamento político. Entretanto, aquilo que parece um ponto final, a morte do líder, traduz-se em fabricação (reinvenção) da vida, agora potencialmente mitificada e capaz de agenciar todo o grupo. Para esses coletivos, portanto, a morte tem assumido novas configurações, imprevistas por seus algozes. 
O impacto visual dos painéis produz a sensação de que aqueles líderes estão ainda presentes entre os camponeses, indígenas, quilombolas e demais grupos rurais, seja através de sua imagem, que acompanha toda a peregrinação, seja por meio das narrativas de suas trajetórias, que começam no momento de seu engajamento político e formação como líder, mas não terminam com o advento da morte. Esta presentificação permite não apenas o acesso à história desses grupos, mas potencializa a continuidade dos seus projetos de vida, alimentados pela reiteração da memória do líder e corporificados nesses painéis. Estes transformam os mártires-encantados, afinal, em intercessores que motivam e mobilizam possibilidades de criação (Deleuze, 1988 apud Gonçalves e Head, 2009, pp. 21-22).

Se tomarmos os líderes mortos como expressão desses diversificados coletivos, rurais e indígenas, poderemos articulá-los num campo perceptivo imbricado de conflitos, enfrentamentos e instabilidades. Envoltos nesses dilemas e nos desdobramentos da vivência cotidiana do grupo, esses mártires-encantados transitariam entre "a figura e o fundo, as margens e o centro, o móvel e o ponto de referência, o transitivo e o substancial, o comprimento e a profundidade" (Deleuze e Guattari, 1992, p. 30).

\section{Algumas considerações}

Esta topologia é uma tentativa de organizar uma lógica de pensamento que reconheça a transição entre vida e morte, articulada pela mediação, tradução e movimentação, expressos e presentificados pela potência/força evocativa das imagens dos mártires, notadamente através de painéis e fotografias.

Nesse ínterim, as imbricações da memória reconhecidas nas narrativas desses grupos e delineadas nas imagens de seus mártires-encantados tencionam transmitir suas experiências de conflitos e enfrentamentos, que perpassam o direito de permanecer em territórios historicamente ocupados e apropriados por esses sujeitos. Espaços legitimados pelo tempo vivido, baseado nas relações que os indivíduos estabelecem com a terra e com recursos advindos dela, pela extração ou pelo tra- balho (cf. Martins, 2009; Godoi, 1998; Woortmann, 1990).

Essas relaçôes poderiam ser qualificadas como de domínio ou maestria, opondo-se à racionalidade oficial, anunciada pela Superintendência de Desenvolvimento da Amazônia (Sudam), Instituto de Terras do Pará (Iterpa), Instituto Nacional de Colonização e Reforma Agrária (Incra), grandes projetos de extração e exploração de recursos naturais e minerais e latifundiários locais, para os quais, somente a titularidade provisória ou definitiva é instrumento de comprovação da propriedade.

Neste escopo, a figura do mártir-encantado é reconhecida como agenciadora de um conceito de propriedade que se baseia no trabalho investido sobre a terra e no projeto de vida desses grupos. Eles podem ser comparados aos mestres-donos, ${ }^{18}$ pela sua capacidade de ação eficaz sobre o mundo, podendo assim ser definidos como mediadores, o que também envolve uma relação de controle e proteção (cf. Fausto, 2008, pp. 330-331).

Essa topologia envolve também um jogo entre singularidade e pluralidade: o dono é uma singularidade plural [...]. O mestre é, assim, a forma pela qual uma pluralidade aparece como singularidade para outros. É nesse sentido que o chefe é um dono. [...] Nesse sentido, mais do que um representante (i.e., alguém que está no lugar de), o chefe-mestre é a forma pela qual um coletivo se constitui enquanto imagem; é a forma de apresentação de uma singularidade para outros (Idem, p. 334).

Em tese, essas imagens transcendem seus grupos e alcançam outras formas de entendimento sobre o conflito, transformadas em tônica do enfrentamento pela terra e pelos projetos de vida desses grupos. Neste movimento, seus líderes são então sacralizados e ritualizados, transfigurando-se em imagem singular de um coletivo, isso implica na transformação do grupo cuja capacidade de reconhecer a ação própria é transferida ao mártir-encantado como uma singularidade magnificada (Idem, p. 335). 


\section{Notas}

1 José Dutra da Costa, o Dezinho, era presidente do STR de Rondon do Pará e foi assassinado em 21 de novembro de 2000, com três tiros, pelo matador de aluguel Wellington de Jesus Silva, que acabou preso em flagrante. O pistoleiro disse que havia recebido 2 mil reais e um revólver para executar o líder sindical (Almeida, 2009).

2 Esse termo de cunho religioso assume configuração política no Brasil a partir do agravamento de situações de conflito no campo, o que culminou com criação em 1975 da Comissão Pastoral da Terra (CPT), ligada à Conferência Nacional dos Bispos do Brasil (CNBB), que procura articular e organizar politicamente os trabalhadores rurais e fazer mediação e intermediação na resolução desses conflitos. Reivindicando as desapropriaçôes de terras com base no Estatuto da Terra, essa instituição atribui aos lideres dos movimentos sociais mortos nesses conflitos uma caracterização sagrada de doação da vida pelas causas sociais da humanidade (Pereira, 2004; Murphy, 2008).

3 Nos termos de Bruno Latour (2009), o coletivo pode ser definido como produçôes de naturezas-culturas, distinguindo esse tipo de coletivo de noçôes já conhecidas de sociedade - homens-entre-si - e de natureza - coisas-em-si - elaboradas por sociólogos ou epistemólogos. Nessa direção, o referido autor parte de uma ideia de relaçōes marcadas por pequenas divisões, nas quais a grande divisão - natureza versus sociedade (cultura) torna-se invisível, na medida em que coligam associaçōes de humanos e de não-humanos (Idem, pp. 104-105).

4 Nesses contextos, o termo "luta" tende a assumir significados distintos, traduzindo açōes tanto do fazer cotidiano quanto dos espaços rituais. Certa ênfase no sofrimento é relacionada à defesa de projetos coletivos de vida, em narrativas nas quais a "luta pela terra" confunde-se com a "luta pela vida"; nelas estão imbuídos sentimentos de pertencimento e coletividade: “[...] o termo luta também é usado por pessoas que se consideram em uma situação excepcionalmente difícil ou que descrevem um período crítico de sua vida. [...] luta é uma noção que qualifica a experiência cotidiana de pessoas que foram atingidas de forma muito desfavorável por processos de transformação no campo e passaram a viver precariamente como assalariados temporários, parceiros em situação muito instável ou tiveram uma difícil experiência de migração" (Comerford, 1999, p. 26).

$5 \mathrm{Na}$ literatura antropológica, os encantados aparecem como pessoas que não morreram ou como força mágica atribuída ao sobrenatural, estando entre suas principais características a invisibilidade aos seres humanos comuns; incorporam-se assim nos pajés ou curadores e podem curar ou provocar doenças (Galvão, 1955, p. 91; Maués, 1992, pp. 203-209; 1999, pp. 92-93). Contudo, experiências etnográficas na Romaria dos Mártires, realizada no nordeste do Mato Grosso em julho de 2011, revelaram outras traduçōes para o termo, reconhecidamente entre povos indígenas que nomeiam seus líderes mortos como "irmãos de luz" ou "encantados".

6 " [...] o tempo histórico de um camponês dedicado a uma agricultura de excedente é um. Já o tempo histórico do pequeno agricultor próspero, cuja produção é mediada pelo capital, é outro. E é ainda outro o tempo histórico do grande empresário rural. Como é outro o tempo histórico do índio integrado, mas não assimilado, que vive e se concebe no limite entre o mundo do mito e o mundo da história. Como ainda é inteiramente outro o tempo histórico do pistoleiro que mata índios e camponeses a mando do patrão e grande proprietário de terra: seu tempo é o do poder pessoal da ordem política patrimonial, e não o de uma sociedade moderna, igualitária e democrática que atribui à instituição neutra da justiça a decisão sobre os litígios entre seus membros. A bala de seu tiro não só atravessa o espaço entre ele e a vítima. Atravessa a distância histórica entre seus mundos, que é o que os separa" (Martins, 2009, p. 139).

7 Conforme Paul Little (2002), cosmografia é a relação particular que cada grupo social mantém com seu respectivo território, a qual define "os saberes ambientais, ideologias e identidades - coletivamente criados e historicamente situados - que um grupo social utiliza para estabelecer e manter seu território. A cosmografia de um grupo inclui seu regime de propriedade, os vínculos afetivos que mantém com seu território específico, a história da sua ocupação guardada na memória coletiva, o uso social que dá ao território e as formas de defesa dele" (Idem, p. 4).

8 A região é composta pelos municípios de Ribeirão Cascalheira, Vila Rica, Serra Nova Dourada, São Félix do Araguaia, Santa Terezinha, Santa Cruz do Xingu, São José do Xingu, Porto Alegre do Norte, Novo Santo Antônio, Luciara, Confresa, Canabrava do Norte, Bom Jesus do Araguaia e Alto Boa Vista.

9 Bispo da Prelazia de São Felix do Araguaia (MT) desde a década de 1970, dom Pedro Casaldáliga, inspirado pela Teologia da Libertação, exerce um importante papel como mediador dos conflitos decorrentes da implementação de grandes projetos latifundiários na região norte do Mato Grosso. 
10 Godoi (1999, pp. 110-113) explora essa relação tempo-espaço entre camponeses no sertão do Piauí. Para a autora, o trabalho da memória possibilita a articulação desses sujeitos num passado como preexistência geral até o presente através de "regiōes de memória". Ou seja, a memória tensiona o envolvimento do indivíduo com o tempo vivido, imbricando passado pessoal e coletivo, na medida em que situa o indivíduo numa ordem geral e estabelece uma continuidade entre ele, o tempo vivido e o mundo.

11 "Caaró é uma romaria que está associada ao martírio dos santos jesuítas Roque González, Afonso Rodriguez e João del Castillo, que trabalharam nas missões jesuítas no século XVII e morreram pelas mãos dos índios. Esses mártires foram canonizados por João Paulo II em 1988. Já a Romaria da Terra é uma romaria itinerante que é promovida especialmente pela pastoral popular por meio da Comissão Pastoral da Terra (CPT), com uma forte conotação política, na linha da Teologia da Libertação" (Steil, 2004, p. 12).

12 As antiestruturas, ou communitas, "fora de" ou "nas periferias da vida cotidiana”, representam o lugar liminar onde se estabelecem relações entre indivíduos concretos, de forma direta e imediata, enquanto a estrutura organiza-se no plano da obrigação institucionalizada (cf. Turner, 1986; 1987; 2005; 2008).

13 A communitas existencial ou espontânea ocorre no "confronto direto, imediato e total entre identidades humanas, que tende a fazer os envolvidos passarem na humanidade como comunidade homogênea, desestruturada e livre"; na normativa, é possível visualizar a organização, em um sistema social permanente e "sob influência do tempo, da necessidade de mobilizar e organizar recursos para manter os membros de um grupo vivos e prosperando", assim como da necessidade de controle social entre membros que almejam metas coletivas; por fim, a communitas ideológica é evidenciada em modelos utópicos de sociedades, "cujos idealizadores acreditam exemplificar ou fornecer as condiçōes ideais para a communitas existencial" (Idem, 158).

14 " [...] O padre João Bosco teve que se converter aos índios. Ele tinha uma formação tradicional. De uma pastoral e de uma teologia tradicionais. Quando entrou em contato com o Cimi nos primeiros momentos ele estava em uma pastoral muito revolucionária, muito diferente de tudo o que se fazia e se conhecia. Ele nos textos escritos tinha palavras muito comovedoras, falando dessa conversão à causa indígena, e nisso também é símbolo, quantos índios. Todos e cada um de nós temos necessidade de uma conversão, nos convertemos a Deus, mas convertendo-nos aos irmãos e completamente aos marginalizados, aos pobres e aos esquecidos, aos desesperançosos. Uma conversão pastoral, estrutural, porque não basta individualmente nos convertemos tem que se converter à estrutura da igreja e à estrutura da sociedade" (dom Pedro Casaldáliga, em entrevista concedida em 15/7/11).

15 Os trabalhos de campo citados foram realizados especificamente nos municípios de São Geraldo do Araguaia (PA), em dezembro de 2010, e Ribeirão Cascalheira (MT), em julho de 2011.

16 Conforme a descrição do painel pelo próprio autor: "Na parte central domina a figura de Cristo, que rompe o arame farpado da cerca do latifúndio. Embaixo, derrotada, toda a classe dominante da época (ditadura militar). Podem ser reconhecidos: Delfim Netto, o capelão do Exército, Márcia Ferreira cantora da Rádio Nacional. Na parte superior: o rio Araguaia, a igreja matriz (inaugurada em 1983) e Xambioá. À esquerda, se aproximando do Cristo estão São João Batista, padroeiro da paróquia, padres Aristides Camio e Francisco Gouriou, dom José Patrick Hanrahan, bispo da diocese da SS. Conceição do Araguaia, e dom Pedro Casaldáliga. À direita, São Geraldo Majella, padres Ricardo Rezende e José Maria Cavalcante Costa, Raimundo Ferreira Lima (o Gringo, líder sindical assassinado em 29 de maio de 1980) e sua esposa, Oneide. Os anos de 1972 a 1993 são anos difíceis para a caminhada da igreja na diocese da SS. Conceição do Araguaia. A causa da Guerrilha do Araguaia (1972-1974) e dos conflitos de terra sofre pressōes, prisōes, torturas e mortes sob o regime militar. Mas a força da fé e da união derruba o poder opressor e os humildes do povo podem cantar vitória. Os padres (Aristides e Francisco) com treze posseiros foram presos (1981) e passaram mais de dois anos na prisão. Em meio à dor, se construiu e inaugurou, com a solidariedade de muitas comunidades do Brasil e de fora do país, a igreja do Cristo Libertador em São Geraldo (1983)".

17 José de Souza Martins (1980) trata esta questão de maneira mais aprofundada.

18 Esta categoria foi analisada por Carlos Fausto (2008) em contextos ameríndios; contudo, é bem apropriada para se pensar as relações de propriedade e domínio encontradas entre camponeses e líderes sindicais assassinados em áreas de conflito fundiário.

\section{BIBLIOGRAFIA}

ALMEIDA, Rogério Henrique. (2009), "Assassinato de sindicalista em Rondon do Pará vai 
ser analisado pela OEA". La Via CampesinaPará, 11 mar. Disponível em laviacampesina-pa.blogspot.com.br/search?q=dezinho, consultado em 10/6/2012.

CARMINATI, Thiago Zanotti. (2011), "Os poderes da imagem fotográfica vistos de Juazeiro do Norte". Anais do Seminário Nacional da Pós-Graduação em Ciências Sociais. Vitória, UFES. Disponível em: periodicos.ufes.br/SNPGCS/article/view/1556/1146, consultado em 30/12/2011.

CASTRO, Eduardo Viveiros de. (2002), A inconstância da alma selvagem e outros ensaios de antropologia. São Paulo, Cosac Naify.

CICCARONE, Celeste. (2003), "Narrativas indígenas Guarani-Mbya”. Contexto, XI (10): 179-195.

COMERFORD, John Cunha. (1999), Fazendo a luta: sociabilidade, falas e rituais na construção de organizaçôes camponesas. Rio de Janeiro, Relume Dumará.

DAMATTA, Roberto \& LARAIRA, Roque de Barros. (1978), Indios e castanheiros: a empresa extrativa e os indios no Médio Tocantins. Rio de Janeiro, Paz e Terra.

DAWSEY, John Cowart. (2005), "O teatro dos boias-frias: repensando a antropologia da performance". Horizontes Antropológicos, 11 (24): $15-34$.

(2006), "Turner, Benjamin e antropologia da performance: o lugar olhado (e ouvido) das coisas". Campos - Revista de Antropologia Social, 7 (2): 17-25. Disponível em ojs. c3sl.ufpr.br/ojs2/index.php/campos/article/ view/7322, consultado em 14/7/2009.

DELEUZE, Gilles \& GUATTARI, Félix. (1992), O que é filosofia? Rio de Janeiro, Editora 34.

ESTERCI, Neide. (1987), Conflito no Araguaia: peões e posseiros contra a grande empresa. Petrópolis,Vozes.

FAUSTO, Carlos. (2008), "Donos demais: maestria e domínio na Amazônia". Mana - Estudos de Antropologia Social, 14 (2): 329-366. Disponível em www.scielo.br/pdf/mana/v14n2/ a03v14n2.pdf, consultado em 4/7/2011.

FIGUEIRA, Ricardo Rezende. (1986), A justiça do lobo: posseiros e padres do Araguaia. Petrópolis, Vozes.
GALLO, Emilio. (2008), Esse homem vai morre: um faroeste caboclo. [Filme-vídeo]. Direção de Emilio Gallo. Brasil. 75 min.

GALVÂO, Eduardo. (1955), Santos e visagens: um estudo da vida religiosa de Itá, Amazonas. São Paulo, Companhia Editora Nacional.

GODOI, Emília Pietrafesa de. (1998), "O sistema do lugar: história, território e memória no sertão", in Ana Maria de Niemeyer e Emília Pietrafesa de Godoi (orgs.), Além dos territórios: para um dialogo entre etnologia indigena, os estudos rurais e os estudos urbanos, Campinas, Mercado das Letras.

. (1999), O trabalho da memória: cotidiano e história no sertão do Piaui. Campinas, Editora da Unicamp.

GODOI, Emília Pietrafesa de \& NIEMEYER, Ana Maria de. (1998), "Apresentação", in (orgs.), Além dos territórios: para um dialogo entre etnologia indigena, os estudos rurais e os estudos urbanos, Campinas, Mercado das Letras.

GODOI, Emília Pietrafesa de \& LOERA, Nashieli Rangel. (2009-2010), "Apresentação". Ruris: Revista do Centro de Estudos Rurais, 3 (2): 9-15. Disponível em www.ifch.unicamp.br/ojs/index.php/ruris/article/view/693/558, consultado em 7/9/2011.

GOLDMAN, Marcio \& LIMA, Tânia Stolze. (1999), "Como se faz um grande divisor?", in Marcio Goldman (org.), Alguma antropologia, Rio de Janeiro, Relume Dumará.

GONÇALVES, Marco Antonio \& HEAD, Scott. (2009), "Confabulações da alteridade: imagens dos outros (e) de si mesmos", in (orgs.), Devires imagéticos: a etnografia, o outro e suas imagens, Rio de Janeiro, 7Letras.

GUERRA, Gutemberg Armando Diniz. (2001), O posseiro da fronteira: campesinato e sindicalismo no Sudeste paraense. Belém, Edufpa.

HÉBETTE, Jean. (2004), "Fluxos migratórios decorrentes da política de desenvolvimento para a Amazônia", in Cruzando a fronteira: 30 anos de estudo do campesinato na Amazônia, Belém, Edufpa, vol. 1.

IANNI, Otávio. (1978), A luta pela terra: história social da terra e da luta pela terra numa área da Amazônia. Rio de Janeiro, Vozes. 
LATOUR, Bruno. (2009), Jamais fomos modernos. Rio de Janeiro, Editora 34.

LITTLE, Paul. (2002), Territórios sociais e povos tradicionais no Brasil: por uma antropologia da territorialidade. Brasília, DAN-UNB (série Antropologia, n. 322).

MÁRQUEZ, Gabriel García. Crônica de uma morte anunciada. Rio de Janeiro, Record, 2012.

MARTINS, José de Souza. (1980), Expropriação e violência: a questão política no campo. São Paulo, Hucitec. (1984), A militarização da questão agrária no Brasil: terra e poder. Petrópolis, Vozes. . (2009), "O tempo da fronteira: retorno à controvérsia sobre o tempo histórico da frente de expansão e da frente pioneira", in

, Fronteira: a degradação do outro nos confins do humano, São Paulo, Hucitec.

MAUÉS, Raymundo Heraldo. (1992), "Catolicismo popular e pajelança na região do Salgado: as crenças e as representações", in Pierre Sanchis (org.), Catolicismo: unidade religiosa e pluralismo cultural, São Paulo, Loyola. . (1999), Uma outra "invenção" da Amazônia: religiōes, histórias, identidades. Belém, Cejup.

MAUSS, Marcel. (2003), "Efeitos físicos no indivíduo da ideia de morte sugerida pela coletividade", in São Paulo, Cosac Naify.

MAUSS, Marcel \& HUBERT, Henri. (2005), Sobre o sacrifício, São Paulo, Cosac Naify.

MURPHY, Roseanne. (2008), Mártir da Amazônia: vida da irmã Dorothy Stang. São Paulo, Paulus.

OLIVEIRA, Roberto Cardoso de. (1976), Identidade, etnia e estrutura social. São Paulo, Pioneira.

PEREIRA, Airton dos Reis. (2004), O papel dos mediadores nos conflitos pela posse da terra na região Araguaia paraense: o caso da fazenda Bela Vista. Dissertação de mestrado. Viçosa, UFV.

SAHLINS, Marshall. (1985), Ilhas de história. Rio de Janeiro, Zahar.

STEIL, Carlos Alberto. (2004), "Catolicismo e memória no Rio Grande do Sul". Debates do NER, 5 (5): 9-30. Disponível em www.lume.ufrgs.br/ bitstream/handle/10183/26588/000427154. pdf? sequence $=1$, consultado em 22/8/2011.
TURNER, Victor. (1986), "Dewey, Dilthey, and drama: an essay in the anthropology of experience", in Victor Turner e Edward Bruner (orgs.), The anthropology of experience, Urbana, IL, University of Illinois Press. - (1987), The anthropology of performance. Nova York, PAJ Publications. . (2005), Floresta de símbolos: aspectos do ritual Ndembu. Niterói, EdUFF. - (2008), Dramas, campos e metáforas: ação simbólica na sociedade humana. Niterói, EdUFF.

VELHO, Otávio Guilherme. (1976), Capitalismo autoritário e campesinato. São Paulo, Difel. (1982), Sociedade e agricultura. Rio de Janeiro, Zahar Editores.

VIEIRA, Maria Antonieta da Costa. (2001), À procura das bandeiras verdes: viagem, missão e romaria; movimentos sócio-religiosos na Amazônia Oriental. Tese de Doutorado. Campinas, Unicamp.

WOORTMANN, Klaas. (1990), “Com parente não se neguceia: o campesinato como ordem moral”. Anuário Antropológico, 87, Brasília. 


\section{A FABRICAÇÃO DE MÁRTIRES- ENCANTADOS E SUAS APROPRIAÇÕES POR COLETIVOS RURAIS E INDÍGENAS}

\section{Edimilson Rodrigues de Souza e Celeste Ciccarone}

Palavras-chave: Conflitos fundiários; Mártires-encantados; Narrativas; Violência; Amazônia.

O foco deste trabalho são as apropriações das imagens de agentes pastorais, religiosos e lideranças sindicais e indígenas, que foram assassinados em regiōes de intenso conflito fundiário. $\mathrm{O}$ enfoque nas imagens em que esses líderes estão representados possibilita aproximações etnográficas, na medida em que articula diferentes linguagens sobre o tema da luta pela terra. Portanto, investir no entendimento da produção destas imagens e das narrativas sobre elas objetiva tentar compreender modalidades de tradução dos significados atribuídos a estas mortes violentas, em regióes de conflitos fundiários, sobretudo, no sentido que elas têm na fundamentação dos atos de luta e resistência.

\section{THE FABRICATION ENCHANTED MARTYRS AND THEIR APPROPRIATION BY RURAL AND INDIGENOUS COLLECTIVITIES}

\section{Edimilson Rodrigues de Souza and Celeste Ciccarone}

Keywords: Land Conflicts; Enchanted Martyrs; Narratives; Violence; Amazon.

The article focuses the appropriation of the images of pastoral workers, religious agents, trade-union and indigenous leaders murdered in regions of intense land conflict. The focus on the images representing those leaders and the narratives associated to them opens the possibility of ethnographic approaches, as they articulate different speeches about the topic of the struggle for land. Thus, the investment in understanding the production of such images and narratives aims at comprehending the modalities of translation of the meanings attributed to those violent deaths in regions of land conflicts, especially in what comes to the sense they have as foundations for the acts of struggle and resistance.

\section{LA CRÉATION DE MARTYRS- ENCHANTÉS ET LEURS DIVERSES APPROPRIATIONS PAR LES COLLECTIVITÉS RURALES ET INDIGÈNES}

\section{Edimilson Rodrigues de Souza et Celeste Ciccarone}

Mots-clés: Conflits fonciers; Martyrs-enchantés; Narratives; Violence; Amazonie.

L'objectif de ce travail est d'analyser l'appropriation des images d'agents pastoraux, de religieux, de leaders syndicaux et indigènes assassinés dans des régions où les conflits fonciers sont intenses. L'accent mis sur les images où les dirigeants sont représentés permet une approche ethnographique dans la mesure où il articule différents langages sur le thème de la lutte pour la terre. Ainsi, investir dans la compréhension de la production de ces images et leurs narratives a pour but de tenter de comprendre les modalités de traduction des représentaions associées à ces morts violentes dans les régions marquées par des conflits fonciers, particulièrement en ce qui concerne le fondement des actes de lutte et de résistance. 